\title{
ESCOLAS NOTURNAS PARA ADULTOS TRABALHADORES - BAHIA -1871-1889
}

Ione Celeste de Sousa ${ }^{1}$

\section{Resumo}

Este artigo investiga as escolas noturnas para adultos trabalhadores na Bahia entre 1870 e 1888 , enquanto parte da escolarização empreendida entre o ano da criação do Conselho de Instrução Pública pela lei 172 de 25 de maio de 1842 e o ano de 1888, da Abolição da escravidão, que juridicamente estabeleceu novas formas de trabalho na sociedade. A vertente teóricometodológica utilizada é uma História Social da Educação com abordagem micro-histórica dos sujeitos. Enfoca evidências sobre diversas aulas e casas de educação da província baiana cujos registros ainda são acessíveis. O critério metodológico foi articular um variado corpus de fontes como ofícios de diversos sujeitos da instrução pública baiana- pais, mestres, inspetores- e fontes oficiais da Diretoria Geral de Instrução Pública como regulamentos de ensino, relatórios de presidentes da província, relatórios de ensino, mapas e quadros estatísticos elaborados por professores a um contexto/ processo específico vivido pela sociedade brasileira/baiana - o débâcle do escravismo em consonância com a crescente preocupação com a formação de um novo trabalhador a partir do categorizado como elemento nacional.

Palavras-chaves: Escolas noturnas baianas. Escolarização. Pobres. Trabalhadores. Província da Bahia.

\section{NURSING SCHOOLS FOR ADULTS WORKERS - BAHIA - 1871-1889}

\begin{abstract}
This article investigates the night schools for working adults in Bahia between 1870 and 1888 , as part of the schooling undertaken between the year of the creation of the Public Instruction Council by the law 172 of May 25, 1842 and the year of 1888, of the Abolition of slavery, which legally established new forms of work in society. The theoretical-methodological aspect used is a Social History of Education with a micro-historical approach of the subjects. Focuses evidence on various classes and houses of education in the province of Bahia whose records are still accessible. The methodological criterion was to articulate a varied corpus of sources such as the offices of several subjects of Bahian public education- parents, teachers, inspectors- and official sources of the General Directorate of Public Instruction such as teaching regulations, provincial presidents reports, teaching reports, maps and statistical tables by teachers to a specific context / process lived by the Brazilian / Bahian society - the debacle of slavery in line with the growing concern with the formation of a new worker from the categorized as a national element.
\end{abstract}


Keywords: Bahia night schools. Schooling. Poor. Workers. Province of Bahia.

\title{
ESCUELAS NOCTURNAS PARA ADULTOS TRABAJADORES - BAHIA - 1871-1889
}

\begin{abstract}
Resumen
Este artículo investiga las escuelas nocturnas para adultos trabajadores en la Bahía entre 1870 y 1888, como parte de la escolarización emprendida entre el año de la creación del Consejo de Instrucción Pública por la ley 172 de 25 de mayo de 1842 y el año de 1888, de la Abolición de la Abundación esclavitud, que jurídicamente estableció nuevas formas de trabajo en la sociedad. La vertiente teórico-metodológica utilizada es una Historia Social de la Educación con abordaje micro-histórico de los sujetos. Enfoca evidencias sobre diversas clases y casas de educación de la provincia bahiana cuyos registros todavía son accesibles. El criterio metodológico fue articular un variado corpus de fuentes como oficios de diversos sujetos de la instrucción pública bahiana-padres, maestros, inspectores- y fuentes oficiales de la Dirección General de Instrucción Pública como reglamentos de enseñanza, informes de presidentes de la provincia, informes de enseñanza , mapas y cuadros estadísticos por profesores a un contexto / proceso específico vivido por la sociedad brasileña / baiana - el débâcle del esclavismo en consonancia con la creciente preocupación con la formación de un nuevo trabajador a partir del categorizado como elemento nacional.
\end{abstract}

Palabras claves: Escuelas nocturnas bahíanas. Escolarización. Pobres. Trabajadores. Provincia de Bahía.

\section{INTRODUÇÃO: ESCOLAS NOTURNAS PARA ADULTOS - UMA ESTRATÉGIA SENHORIAL NOS ANOS 1870.}

Este artigo tem como tema de investigação a criação de aulas noturnas na Província da Bahia como parte das estratégias de disciplina, controle e profissionalização de trabalhadores nacionais nos últimos anos do escravismo. Para sua elaboração utilizo como fontes os relatórios de presidentes da província da Bahia, relatórios de diretores da instrução pública, relatórios de professores, mapas de alunos e de aulas públicas; Atos do Governo e livros de registro de aulas públicas. Também faz parte do conjunto de fontes utilizadas ofícios de professores, de inspetores literários e de pais de alunos.

O texto apresentado se insere no campo da História Social da Educação com interesse na implantação, difusão e consolidação da escola pública para as camadas subalternizadas no Brasil. Objetiva rastrear a expansão da escolarização para as mesmas enquanto estratégias de 


\section{Revista HIISTINIDIBR On-line}

dominação, mas também, como táticas dos subalternizados pelo acesso à educação/instrução ao enfocar as tentativas de acesso às aulas noturnas, como os problemas relativos à frequiência de trabalhadores ante as contingências das atividades laborais e a presença de sujeitos na faixa dos 14 aos 18 anos, que eram formalmente proibidos de freqüentar as aulas públicas diurnas, mas que legalmente não eram adultos na legislação imperial.

O artigo busca o diálogo entre a historiografia da educação com problemáticas da historiografia sobre trabalho e pobres urbanos, quanto aos anos finais do Império brasileiro, e a instrução dos pobres como parte de um conjunto de estratégias de controle e disciplinamento sobre os subalternizados.

A criação das aulas ou escolas noturnas para os trabalhadores, nos espaços urbanos ou ruralizados, representa um arsenal de estratégias para forjar um trabalhador disciplinado, civilizado, morigerado. E que estas estratégias não ficaram restritas às conscrições diretas do trabalho, como a obrigação do uso de tabuletas de identificação no pescoço dos ganhadores em 1857, que resultou numa "[...] greve negra." (REIS, 1993, p. 6-29). Vinte e cinco anos depois, em 1882, outra tentativa foi efetuada via a obrigatoriedade de matrícula em livros específicos para esta mesma categoria de trabalhadores, com registros de sinais corporais de identificação, investigada pelo mesmo autor (REIS, 2000). Considero que as práticas de educação e instrução também foram constitutivas deste esforço.

Ressalto que, implantadas a partir dos interesses dos governantes, as escolas e aulas noturnas para adultos e trabalhadores foram procuradas e apropriadas de diferentes formas pela população pobre e trabalhadora.

Institucionalmente, as escolas noturnas para adultos e trabalhadores foram instaladas na província da Bahia, todas de primeiras letras, em outubro de 1871 no contexto das reformas administrativas elaboradas pelo visconde de São Lourenço, Francisco Gonçalves Martins, político conservador baiano (NUNES, 2004) durante o ano de 1870. Estas reformas incidiram sobre três ramos do serviço público da época- o judiciário, o policial e o da instrução pública. A escolha por estes três aspectos da vida social apontam a uma preocupação com as ações dos sujeitos quanto à moral e os costumes.

Dez anos depois o Reverendo Romualdo Maria de Seixas Barroso, no relatório anexo ao de João Lustosa da Cunha Paranaguá, explicitou que o intuito da criação das aulas noturnas para os trabalhadores adultos fora possibilitar a frequiência daqueles que foram indicados como os que "[...] deixaram de aprender na infância." (BARROSO, 1882, p. 12). 
Anteriormente em 1872, um ano depois da instalação das primeiras aulas públicas noturnas para trabalhadores, o desembargador Antonio Araujo de Freitas Henrique as apoiou, registrando que,

É uma idéa que tem sido geralmente bem acceita.

A freqüência tem sido regular, termo médio, 881 individuos, sendo 547 nas que foram creadas pelo governo e 312 nas que foram espontaneamente creadas pelos professores e outras pessoas. Muitos professores tem pretendido abrir curso nocturno, e lhes tem sido permittido com a condição de não prejudicarem as cadeiras que regem. (FREITAS HENRIQUES, 1872, p. 69-70).

Nos relatórios dos presidentes da província as escolas noturnas ou aulas noturnas foram registradas em item específico, destacado sob o título Escholas para Adultos, indício da importância dada às mesmas no projeto de escolarização baiana em curso nos anos 1870/90, com maior incidência entre 1872 a 1889. Na primeira mensagem do governo republicano não foram registradas. Em 1891 desapareceram deste tipo de documento. Entre 1909/1915 voltaram a ser registradas nos relatórios dos delegados escolares, com o mesmo significado.

Quanto ao provimento financeiro as escolas noturnas tanto podiam ser públicas, mantidas e providas pelo governo provincial, como também privadas. Estas eram sustentadas pelo pagamento dos freqüentadores, com uma possível subvenção de pessoas beneméritas da sociedade. Para sua criação e continuidade foi estabelecida uma frequiência mínima 30 de alunos, contra a frequiência exigida de 20 alunos nas aulas diurnas. Também era exigida uma matrícula maior, que deveria alcançar quarenta e cinco alunos versus os quarenta exigidos nas aulas diurnas.

Em termos de tempo de aula, as escolas noturnas tinham também um horário menor que das aulas diurnas, que se desdobravam em dois turnos de três horas consecutivas. Começavam pela manhã, às $09 \mathrm{hs} 00$ até as $12 \mathrm{hs} 00$ horas. $\mathrm{O}$ turno da tarde iniciava às $14 \mathrm{hs} 00 \mathrm{e}$ findava às $17 \mathrm{hs} 00$. Em contrapartida a noite as aulas iniciavam às $19 \mathrm{hs} 00 \mathrm{com}$ término às $21 \mathrm{hs} 00$, portanto com $1 / 3$ do horário das aulas diurnas.

Como seu período era menor, o ordenado do professor que atuava nas mesmas seguiu o tempo estrito das aulas. Assim, o valor a ser percebido pelo professor das aulas noturnas foi fixado como sendo "[...] mediante uma gratificação correspondente á metade do ordenado das aulas diurnas." (ROCHA, 1872, p. 10). Este reduzido salário gerou tensões entre o professorado. No ano seguinte a instalação das aulas noturnas, em 1872, Francisco Jose da Rocha, dirigente do ensino provincial, defendeu que as escolas diurnas adotassem um horário corrido, das $8 \mathrm{hs} 00$ às $14 \mathrm{hs} 00$, sob o duplo argumento de que esta mudança permitiria aos pais programarem um horário de auxilio dos filhos nas suas "[...] atividades de subsistência ou laborais." (ROCHA, 1872, p. 10). 
Contudo, o central na sua defesa quanto à unificação das aulas diurnas em tempo único e corrido, era que este possibilitaria que os professores públicos primários que atuavam no diurno abrissem aulas noturnas "[...] menos cansados que quando obrigados a seguirem o regime de aulas matutinas e vespertinas." (ROCHA, 1872, p. 10). Tal proposta encobria o interesse do governo provincial em ampliar as escolas noturnas, sem ampliar o quadro de professores e suas despesas ao destacar a questão dos melhoramentos na carreira do magistério como favor no jubilamento, a então aposentadoria, ou gratificações e prêmios,

D'esta maneira poderiam os professores mais dedicados, nos logares populosos, que garantissem uma frequencia regular de adultos, abrir cursos nocturnos, sem ônus para a Província, e apenas mediante algum melhoramento ou favor na sua jubilação, ou se contasse rasoalvelmente o tempo, mediante certa escala preestabelecida, de modo viesse a obtel-a antes do termo que a lei lhe marca, ou com alguma differença nos honorários, ou ainda com uma simples gratificação annual, como se dá aos que leccionam além de um certo tempo. (ROCHA, 1872, p. 10).

\section{A INSTALAÇÃO E O FUNCIONAMENTO DAS ESCOLAS NOTURNAS PARA ADULTOS}

Quanto ao contexto de criação destas aulas noturnas é consenso na historiografia da educação brasileira que na década de 1870 cresceu a procura por trabalhadores que dominassem as bases da leitura, escrita e execução de contas primeiras letras. Sobre este campo a maior parte das evidências utilizadas pelos historiadores continuam sendo os Relatórios de Presidentes de Províncias e dos Ministros. Nestes estão evidentes os registros quanto ao interesse em escolarizar o elemento nacional e os imigrantes pobres, no intuito de dinamizar a agricultura assim como de moralizá-los.

Porém, é importante destacar que estes mesmos sujeitos buscaram variadas formas de dominar as habilidades oferecidas pela escolarização tanto para penetrar no mercado de trabalho, assim como destacar os significados que deram ao letramento. Por outro lado, é também inportante ressaltar os interesses do patronato agrícola, comercial e industrial por estes sujeitos aptos a atuar nas atividades econômicas mais complexizadas. Muitas entidades patronais apoiaram a criação de aulas noturnas e cursos de ofícios.

Conforme as pesquisas no campo temático vêem indiciando, a prática de implementação /implantação de escolas noturnas, muitas vezes com a especificação de que se destinavam aos adultos trabalhadores, foi uma estratégia comum em várias das províncias no final do oitocentos como parte do projeto de escolarizar os pobres, o povo. 


\section{Revista HIISTINIDIBR On-line}

Dentre a produção historiográfica, o tema foi inicialmente investigado por Ananias (2000), Peres (1996) e Schueler (1997), que enfocaram respectivamente aulas noturnas em Campinas, São Paulo; Pelotas, Rio Grande do Sul; e no município da Corte, Rio de Janeiro focando as décadas de 1870 a 1890. Estas pesquisas permitem afirmar que a criação de escolas, aulas ou cursos noturnos estiveram inseridas no movimento de educar os trabalhadores livres pobres e os libertos na imediata pós abolição. Podiam ser escolas e aulas particulares existentes em Campinas e Pelotas, mistas como Schueler (1997) investigou no Rio de Janeiro e Sousa (2006) para a Bahia.

Anteriormente a estes trabalhos Freire (1989) realizou uma discussão menos empírica, e mais descritiva e panorâmica, de uma construção histórica da exclusão social no Brasil na perspectiva de uma das vertentes do materialismo histórico, o estruturalismo althusseriano. Seu argumento central foi não ter existido projetos públicos de alfabetização antes do movimento escolanovista.

Dentre as pesquisas mais atuais, Costa (2007) em investigação sobre as aulas noturnas no município da Corte, poeticamente destacando o uso da luz das lamparinas, elemento chave da cultura escolar material desta experiência. Seu argumento é que naquele contexto ocorreu a invenção do analfabeto enquanto lugar social e que a escola noturna não foi criada para extinguir o analfabetismo, mas "[...] para organizar, hierarquizar saberes e posições sociais." (COSTA, 2007, p. 03).

Não a invenção da condição de iletramento, mas do lugar social de sujeito ignorante, infantilizado, vicioso, que precisava "ser regenerado", "preparado para vida política", para a "vida civilizada", "libertado das trevas da ignorância", etc. E é sobre tal invenção que o projeto-político-pedagógico elitista se constrói. (COSTA, 2007, p. 02).

A autora também evidencia que entre as instituições que criaram e mantiveram escolas noturnas na corte imperial destacou na sua pesquisa de mestrado o Liceu de Artes e Ofícios; a Sociedade Auxiliadora da Indústria Nacional; o Clube dos Libertos contra a Escravidão.

Sousa (2006), em tese de doutorado sobre a escolarização de pobres e a cultura escolar na província da Bahia, entre 1870/1890, destacou três sujeitos e suas experiências: primeiro, os presos da Casa de Prisão com Trabalho, problematizando a representação da instrução como regeneração nos discursos jornalísticos e oficiais. Segundo, investigou os embates pela garantia da frequiência dos ingênuos às salas de aula e o direito destes sujeitos à instrução pública como constitutivos das táticas abolicionistas de professores primários, focando ainda as ações de dois padres que dirigiram a instrução pública entre 1878 e 1885 . Terceiro, adultos trabalhadores e a criação e implantação das escolas noturnas para estes em 1871. Seu argumento é que estas aulas tinham como objetivo instruir nas primeiras letras os trabalhadores e melhorar sua formação nos 


\section{Revista HIISTINIDIBR On-line}

ofícios. Além deste aspecto mais técnico, as aulas noturnas visavam moralizar os trabalhadores através da articulação entre a catequese católica e os ideais de civilização em voga na época.

Enfocando o período imediatamente posterior ao deste artigo, Nogueira (2012) analisou a implantação da escola noturna em Minas Gerais nos anos iniciais da república - de 1891 a 1924- com o objetivo de analisar a configuração da política de instrução primaria noturna para os trabalhadores. Sua hipótese de investigação é que uma política educacional foi criada no período republicano para adultos com o apoio do poder público, das associações de classe e das indústrias têxteis que se desenvolviam.

A mesma autora retomou a temática em artigo sobre as imbricações entre a filantropia e as escolas noturnas em Minas Gerais. Argumentou que década de 1870 foi marcada pelo interesse no ensino elementar, em todo o país, na construção de novos projetos de controle social

A partir da década 1870 é notório o interesse que se manifestou em relação à difusão do ensino elementar por todo o país, com especial atenção à forte presença de particulares e de associações civis na criação e manutenção de aulas noturnas para um público comum em todas as províncias onde foram criadas: homens adultos, livres, libertos e escravos. (NOGUEIRA, 2015, p. 130).

Um desdobramento quanto à criação das escolas noturnas para adultos é a pesquisa de Mac Cord (2012) que enfoca as atividades e experiências do mutualismo dos artífices, homens de côr não escravos, do ramo de edificações no Recife oitocentista, na Sociedade das Artes Mecânicas, criada em 1841. Nesta foi instalada uma aula noturna para promover entre os membros e seus familiares a instrução, que o autor considera a ferramenta desses homens era a instrução e a valorização do seu trabalho, livre e qualificado em uma sociedade escravista.

Mac Cord problematizou que a Sociedade das Artes Mecânicas, enquanto associação, valorizava e se preocupava com o progresso e a civilização do trabalhador nacional e estabeleceu como um dos seus objetivos o "[...] aperfeiçoamento de seus associados [...]" via a implementação de “[...] duas aulas noturnas, de caráter teórico." (MAC CORD, 2012, p. 30).

$\mathrm{Na}$ esteira de pesquisar as articulações entre trabalho, educação e escravidão Mac Cord, Araujo e Gomes (2017), organizaram uma coletânea que trata de diversas experiências de letramento e ensino no Brasil escravista e que perpassa o tema das aulas noturnas, ainda que não explicitamente enfoque estas.

Também transversalmente a investigação sobre as escolas noturnas Rizzini (2004, p. 02) ao pesquisar sobre a educação para meninos desvalidos, na Corte e na região amazônica ressaltou que foram poucas as inovações e mudanças na educação para o povo no final do seculo XIX, salvo a criação de aulas noturnas para trabalhadores. 


\section{Revista HIIS'THDBR On-line}

Uma pesquisa que enfocou detidamente a implantação de cursos noturnos para adultos foi a efetuada por Peres (1996) investigando Pelotas, RS. Em outro artigo Peres (2001) sinalizou que o interesse em educar trabalhadores, adultos e pobres, esteve no bojo das preocupações das elites na segunda metade do século XIX, no intuito de fomentar com as competências do para as novas atribuições e mediações de produção, com quantificação métrica no estocamento, distribuição ou elaboração de produtos industriais.

A referida autora destacou que a estratégia dos cursos noturnos e das escolas noturnas públicas para adultos e trabalhadores, instaladas pelos governos provinciais e associações de ofícios, como foi a experiência baiana do Liceu de Artes e Ofícios, são constituintes da própria escolarização para a população adulta e jovem, popular, ao delimitarem desde seu início estes sujeitos como alvos de suas estratégias e projetos, o que na sua análise se perpetua até os dias atuais, ofertando cursos basicamente para trabalhadores de variadas etapas etárias. (PERES, 1996).

Em artigo sobre as aulas noturnas da Biblioteca Pelotense aponta à pertinência de focar os indícios de frequiência nas aulas noturnas de sujeitos na faixa dos 13 aos 18 anos, assim como de possíveis escravos e mulheres (PERES, 2001). Para, Peres (2001) foi essencial perceber nesta implantação das aulas noturnas na década de 1870 a relação com o liberto e o ingênuo e com os debates do processo abolicionista.

Seguindo estas proposições de pesquisa, Sousa (2006) para a Bahia rastreou escolas noturnas ou aulas noturnas como umas das possibilidades da escolarização dos pobres. E dentre as questões destacou na criação destas escolas noturnas públicas para trabalhadores no decênio de 1870 como uma das táticas do emacipacionismo progressivo. Apontou que esta preocupação sobre a educação e a instrução do elemento nacional cresceu e incorporou três outros sujeitos, quais fossem, o liberto, o ingênuo e o imigrante.

Destacou ainda a importãncia na decada posterior de instruir o povo comouma das tensões nas disputas eleitorais após a lei de janeiro de 1881 que restringiu o voto aos alfabetizados, numa sociedade de de analfabetos, mendigos, escravos e mulheres. Perfilados pelo Presidente da Província, o Dr. Francisco Gonçalves Martins, quando da apresentação da reforma da Instrução Pública, como os que procuravam [...] expedientes reparatórios [...] (MARTINS, 1870, p. 18) ante a impossibilidade que experienciaram de estudar na infância.

$\mathrm{Na}$ pesquisa que baseia este artigo encontrei evidências quanto as preocupações referentes ao saber "ler e escrever" para votar na elite baiana, pois era extremamente baixa a taxa de alfabetização oficial. Em 1881 a Bahia com "[...] 1.500 .000 habitantes, e conta com 574 cadeiras publicas de instrucção primaria, tem apenas uma inscripção escholar de 21.626 alumnos.” (BARROSO, 1881, p. 09). 


\section{Revista HIISTINIDIBR On-line}

ISSN: 1676-2584

Artigo

doi: $10.20396 /$ rho.v18i2.8645891

Os indícios permitiram argumentar que na província da Bahia esta articulação entre a criação das aulas públicas noturnas e a criação de estratégias para o uso político do voto do cidadão foi presente desde a Reforma de Instrução Pública de 1870 quando foi também implantada a Aula Primaria Elementar da Casa de Prisão com Trabalho. (SOUSA, 2014; 2006)

[...] instrucção primaria que merecce os cuidados da Constituição brasileira, disse que ella era a base de todo o progresso, a condição essencial das instituições políticas de um povo livre, especialmente si consagram o voto quase universal nas urnas. Sem a leitura e a arte de escrever não pode o cidadão tomar parte activa nos differentes processos de eleição, nos conselhos da guarda nacional, e na importantíssima instituição do jury [...]. (MARTINS, 1870, p. 18).

Porém, quem era este livre nacional? Eisenberg (1989) analisou as representações sobre o mesmo em textos de viajantes, para os dois últimos quarteis do oitocentos, quase sempre caracterizados cunhando a categoria homens esquecidos em análise pioneira sobre o oeste paulista, em especial a região de Campinas.

Em análise próxima, Barreiro (2002) destacou os discursos pejorativos sobre o livre nacional em textos análogos, escritos por sujeitos europeus, com outras percepções espaciais e temporais do disciplinamento do trabalho, bastante diferenciadas dos modos de fazer dos livres brasileiros "Muito do imaginário das classes subalternas estava assentado no costume e na tradição e articulado a práticas envolvendo uma relação com a natureza inteiramente voltada à satisfação de suas necessidades energéticas." (BARREIRO, 2002, p. 16).

Acrescentar a estas peculiriadades de modos de fazer a negativização do labor continuada no ethos social brasileiro, constituída em mais de três seculos do uso da escravidão e a sua articulação na recusa do nacional em se engajar ao trabalho esperado. A ressaltar, contudo, que tais registros não devem significar que os nacionais fossem atavicamente preguiçosos, como a literatura de vaigem registrava, mas destacar as diferentes concepções de trabalho, seus usos e apropriações da riqueza produzida.

Mudar o imaginário negativizado do trabalho nas camadas populares foi uma batalha empreendida por legisladores e políticos; juristas, sanitaristas, higienistas e engenheiros; educadores, enfim, um um exército empenhado em mudar via disciplina de trabalho e interferencia brutal nos modos de vida, as formas de agir, ser, pensar e sentir.

O olhar atual da produção historiográfica sobre aqueles anos terminais do Império, destaca a percepção por parte dos sujeitos da importancia de refazer cadeias de controle sobre os subalternizados, dentre aquelas o uso da educação e a instrução. Contudo o pretendido e prescrito como Instrução/Educação às camadas trabalhadoras restringia-se ao mínimo da habilidades da escolarização, e por isto o uso do termo elementar ou primária. 


\section{Revista HIIST'TEIDBR On-line}

ISSN: $1676-2584$

Artigo

doi: $10.20396 /$ rho.v18i2.8645891

A destacar que o uso do termo refere a educação moral, ao cultivo de práticas católicas na formação da familia, nas sociabilidades, no abandono dos charivaris e batuques, de acatamento a legalidade estrita da propriedade individual,enfim, o que exprimia o reverendo Barroso “[...] uma instrucção reparadora, na phrase do Villemain." (BARROSO, 1883, p. 27).

Neste processo, em 1872, ano seguinte a criação das escolas noturnas para adultos, frente a Assembléia Provincial, Antonio Araujo de Freitas Henrique enfatizou que as aulas noturnas cresceram "[...] número de onze, e que mais quinze tinham sido criadas por iniciativa de particulares [...]". Registrou também a "[...] espontaneidade de professores [...]". (FREITAS HENRIQUES, 1872, p. 69-70). Interessante ressaltar que o número de particulares evidencia uma demanda dos próprios trabalhadores, pois eram, escolas e aulas particulares, mantidas pelos alunos.

Porém, é importante também ressaltar que foram palco de disputas por diferentes projetos de educar e de sociedade, com seus usos apropriados de diferentes formas pelos diversos sujeitos envolvidos nas tensões sociais. Estas podem ser percebidas no trecho desta fonte quando escreveu "Tenho me abstido de crear taes aulas, não so para evitar augmento de despezas, como por não me julgar para isso autorisado", (FREITAS HENRIQUES, 1872, p. 6970).

As primeiras dez escolas noturnas foram instaladas no ano de 1871, na capital da província. As fontes que registram sua criação e instalação são os Atos do Governo e os Livros de Registro de Aulas Públicas, além dos relatórios dos presidentes da província da Bahia. No quadro abaixo apresento o nome da Escola Noturna, a localidade onde foi implantada e as observações referentes ao seu primeiro provimento.

Quadro 01 - Escolas noturnas da cidade do Salvador

\begin{tabular}{|c|c|c|}
\hline NOME & LOCALIDADE & OBSERVAÇÕES \\
\hline 1-Não consta & $\begin{array}{l}\text { Freg de Sant'Anna } \\
\left(1^{\mathrm{a}} \text { lettras }\right)\end{array}$ & $\begin{array}{l}\text { Por acto do Gov }{ }^{\circ} \text { de } 4 \text { de Setembro de } 1871 \text { foi creada esta } \\
\text { eschola nocrturna } \mathrm{p}^{\mathrm{a}} \text { adultos. } \\
\text { Em } 6 \text { de } \mathrm{m}^{\circ} \mathrm{m} \text { mez e anno foi nomeado o cidadão Aristides } \\
\text { Guedes Cabral, } \mathrm{p}^{\mathrm{a}} \text { reger esta cadeira co mo substituto. }\end{array}$ \\
\hline 2-Não consta & $\begin{array}{l}\text { Freg de } \\
\text { São Pedro } \\
\left(1^{\mathrm{a}} \text { lettras }\right)\end{array}$ & $\begin{array}{l}\text { Foi creada esta eschola nocturna } \mathrm{p}^{\mathrm{a}} \text { adultos p. acto de } 9 \text { de } \\
\text { Outubro de } 1871 \text { ficando incumbido de rege-la o professor } \\
\text { particular Candido Ricardo de Sant'Anna, que para isso se } \\
\text { offerecera gratuitamente incorrendo com caza e mobílias, } \\
\text { conforme seu off }^{\circ} \text { dirigido ao } \text { Gov }^{\circ} \text { em } 5 \text { de agosto ultimo. }\end{array}$ \\
\hline 3-Não consta & $\begin{array}{l}\text { Freg da Sé } \\
\left(1^{a} \text { lettras }\right)\end{array}$ & $\begin{array}{l}\text { Foi creada esta cadeira p. acto de } 23 \text { de outubro de } 1871, p \text {. } \\
\text { ser freqüentada a eschola nocturna desta freguesia p. crescido } \\
\text { numero de alumnos. }\end{array}$ \\
\hline
\end{tabular}




\section{Revista HIIST'NADBR On-lime}

Quadro 01 - Escolas noturnas da cidade do Salvador

\begin{tabular}{|c|c|c|}
\hline & & $\begin{array}{l}\text { Por Portaria desta Directoria de } 24 \text { de Outubro de } 1871 \text { foi } \\
\text { nomeado o cidadão João } \mathrm{J}^{\circ} \text { de Britto p. provisoriamente reger } \\
\text { esta cadeira. }\end{array}$ \\
\hline 4 & $\begin{array}{l}\text { Freguesia de Santo } \\
\text { Antonio } \\
\left(1^{\mathrm{a}} \mathrm{s} \text { lettras }\right)\end{array}$ & $\begin{array}{l}\text { Foi creada esta eschola } \mathrm{p}^{\mathrm{a}} \text { adultos por acto do } \mathrm{Gov}^{\circ} \text { de } 23 \text { de } \\
\text { outubro de } 1871 \text {. } \\
\text { Por Portaria d'esta Directoria de } 24 \text { de Outubro de } 1871 \text { foi } \\
\text { nomeado o alumno met Adelino da } \mathrm{S}^{\mathrm{a}} \text { e Oliveira para } \\
\text { provisoriam }{ }^{\mathrm{a}} \text { reger esta Cadeira. }\end{array}$ \\
\hline 5 & $\begin{array}{l}\text { Freg }^{\mathrm{a}} \text { da Conceição } \\
\text { da Praia ( } 1^{\mathrm{a}} \mathrm{s} \text { lettras) }\end{array}$ & $\begin{array}{l}\text { Por acto de } 23 \text { de Outubro de } 1871 \text { foi creada esta eschola } \\
\text { nocturna } \mathrm{p}^{\mathrm{a}} \text { adultos. } \\
\text { Por Portaria desta Directoria de } 24 \text { de Outubro de } 1871 \text { foi } \\
\text { nomeado o cidadão Aurélio Benigno Castilho } \mathrm{p}^{\mathrm{a}} \\
\text { provisoriam }{ }^{\mathrm{a}} \text { reger esta cadeira. }\end{array}$ \\
\hline 6 & $\begin{array}{l}\text { Rua do Paço e Pilar } \\
\text { (1ªs lettras) }\end{array}$ & $\begin{array}{l}\text { Por acto do Gov }{ }^{\circ} \text { de } 6 \text { de Novembro de } 1871 \text { foi creada esta } \\
\text { eschola nocturna } \mathrm{p}^{\mathrm{a}} \text { adultos. } \\
\text { Por acto desta Directoria na mesma dacta foi nomeado o } \\
\text { Pharmaceutico Asterio Marques de Oliveira } \mathrm{p}^{\mathrm{a}} \\
\text { provisoriamente reger esta eschola. }\end{array}$ \\
\hline 7 & $\begin{array}{l}\text { Freg da Victoria } \\
\left(1^{\mathrm{a}} \mathrm{s} \text { lettras }\right)\end{array}$ & $\begin{array}{l}\text { Por acto do Governo de } 6 \text { de Nbr de } 1871 \text { foi creada esta } \\
\text { eschola nocturna para adultos. } \\
\text { Por acto desta Directoria da mesma dacta } \\
\text { foi nomeado o cidadão Antonio J }{ }^{\mathrm{a}} \text { da Silva Guimarães } \mathrm{p}^{\mathrm{a}} \\
\text { provisoriam }{ }^{\mathrm{a}} \text { reger esta cadeira }\end{array}$ \\
\hline 9 & $\begin{array}{l}2^{\circ} \text { Distrito de } \mathrm{St}^{\circ} \\
\text { Antonio }\left(1^{\mathrm{a}} \mathrm{s}\right. \\
\text { lettras) }\end{array}$ & $\begin{array}{l}\text { Por acto do Governo de } 30 \text { de Outubro de } 1871 \text { foi creada } \\
\text { esta eschola nocturna para adultos. } \\
\text { Por acto desta directoria de } 31 \text { do } \mathrm{m}^{\circ} \mathrm{m}^{\circ} \text { mez e anno foi } \\
\text { nomeado o cidadão João Joaquim de Souza Bahiense a } \\
\text { provisoriam }{ }^{\circ} \text { reger esta cadeira. } \\
\text { Por acto do Gov de } 16 \text { de fev }^{\circ} \text { de } 1872 \text { foi suppressa esta } \\
\text { cadeira p. falta de alumnos. }\end{array}$ \\
\hline 10 & $\begin{array}{l}\text { Freg da } \text { Se. } \\
\left(2^{a} \text { cadeira }\right)\end{array}$ & $\begin{array}{l}\text { Eschola Nocturna p. adultos creada p. acto do Gov de } 13 \text { de } \\
\text { junho de } 1871 \text {. } \\
\text { Por acto desta Directoria de } 22 \text { do dito mez e anno foi } \\
\text { nomeado o } \mathrm{al}^{\circ} \mathrm{m}^{\circ} \mathrm{Argiro}^{\circ} \text { dos } \mathrm{St}^{\circ} \mathrm{s} \text { Machado Malhado } \mathrm{p}^{\mathrm{a}} \\
\text { substituto desta cad em virtude do q } \sim \text { determinou o Gov / p. } \\
\text { desp }^{\circ} \text { de } 19 \text { do já referido mez. } \\
\text { Por acto do Gov de } 23 \text { de outubro de } 1871 \text { foi dividida esta } \\
\text { cadeira em vista do crescido numero de alumnos q a } \\
\text { freqüentam. }\end{array}$ \\
\hline
\end{tabular}

Fonte: Freitas Henriques, 1872. Quadro elaborado pela autora.

Nestas primeiras escolas noturnas ocorreu, logo após sua instalação, o desmembramento da situada na Freguesia da Sé em duas ante a demanda de matrícula de alunos. Esta era a 


\section{Revista HIISTINIDIBR On-line}

principal e mais movimentada freguesia da cidade de Salvador. Nascimento (1986, p. 69) ao tratar desta freguesia da Sé indicou a maciça presença de trabalhadores pobres que moravam, labutavam, circulavam nas ruas ao descrever que o trabalho.

Logo a seguir a mesma tática foi efetuada naquelas situadas nas freguesias de São Pedro Velho e Vitória, que segundo Nascimento (1986) também eram habitadas por muitos livres pobres criados dos solares elitizados ali existentes. Por fim, foram também criadas escolas noturnas para adultos nos dois distritos da freguesia de Santo Antonio além do Carmo, o primeiro constituído pela praça da sede da igreja, com o orago do mesmo nome, e ruas próximas.

Seu segundo distrito ainda concentrava atividades de agricultura no cinturão rural da cidade e compreendia as estradas de ligação com o interior da Província, nos termos da capela do Resgate pelas trilhas de mata de Narandiba, Barreiras e Beiru. Por baixo, bordejando o rio Camurujipe, pelo Campo do Retiro, ou subindo pela da estrada das Boiadas e do Caminho de Nossa Senhora de Itapagipe de Cima e pelo dique do engenho da Conceição, limitava até a fronteira com a freguesia rural de são Bartolomeu de Pirajá.

Por baixo, beirando a restinga do mar, estavam as freguesias da Penha e dos Mares, Nascimento (1986) habitadas por marítimos e artesãos ligados à pesca, assim como aqueles que praticavam atividades referentes às nascentes manufaturas de transformação.

Em termos de instalação de uma escola ou aula noturna, logo após a criação pelo ato do governo da província, era nomeado um professor, com preferência um aluno-mestre, formado na Escola Normal da capital. Eram considerados adaptados ao magistério, por realizado ocurso normal do Externato dos Homens e cursado as suas disciplinas fossem as "scientificas" ou fossem os “[...] methodos de ensino [...]". (LOBO, 1879, p. 02). Sobre tal prescrição o reverendo Emílio Lobo, então diretor de instrução, defendeu "[...] uma vez que aos alumnos-mestres exclusivamente fosse comettida a melindrosa tarefa do magistério primário." (LOBO, 1879, p. 08). Contudo, apenas duas das iniciais foram providas via ato da presidência da província com um aluno-mestre para regê-las: Adelino da $S^{a}$ e Oliveira, para o $1^{\circ}$ distrito de Santo Antonio; além do Carmo. E Argiro Machado Malhado, para a freguesia da Sé, no desmembramento da sua $2^{\mathrm{a}}$ cadeira.

Os registros trazem evidências que nas outras aulas noturnas os professores não foram alumnos -mestres vide o uso genérico de cidadão para os identificar. Dentre estes, um farmacêutico, Asterio Marques de Oliveira, nomeado para a aula conjunta da freguesia do Passo e Pilar. Para aquela de São Pedro foi nomeado um já atuante professor de aulas particulares, Candido Ricardo de Sant'Anna. Há o registro que efetuou a sua regência de forma gratuita, fornecendo mobilias e casa de uso, possivelmente as measmas de uso na sua aula diurna particular. 


\section{Revista HIIST'TEIDBR On-line}

O regulamento de ensino de 1873, que normatizou a reforma da instrução de 1870 , prescreveu no artigo 76 que as "Aulas nocturnas da capital ou outras que de futuro forem creadas, serão regidas pelos professores públicos das respectivas parochias mediante uma gratificação correspondente á metade do ordenado.” (ALMEIDA COUTO, 1873, p. 19). A prioridade passou a ser de um aluno-mestre ou do professor ja atuante na paroquia.

Importantes são as evidências do interesse de abrir escolas noturnas, nas paróquias e freguesias. Além da subvenção agregada ao vencimento, indicia a existência de público ante uma realidade que até pouco tempo antes proibia a frequência nas aulas públicas diurnas dos maiores de 14 anos.

As escholas nocturnas são de recente creação, e tem sido mui bem acceitas. Vários professores tem-as aberta espontaneamente, e muitos logares as pedem. A concurrencia de alumnos tem coroado a experiência de modo que não se pode deixar de depositar nellas muitas esperanças. (ROCHA, 1872, p. 09).

Este diretor de instrução pública, Francisco Jose da Rocha, em seu relatório de 1872, registrou valiosas evidências a partir de informações dos mapas de aulas que eram obrigatórios desde 1842.

Quadro 02 - Freqüência das escolas noturna para adultos em Salvador- 1871

\begin{tabular}{|l|l|}
\hline $1^{\text {a }}$ cadeira da Sé & 90 \\
\hline $2^{\text {a }}$ cadeira da Se & 67 \\
\hline S. Pedro & 32 \\
\hline Sant'Anna & 43 \\
\hline Conceição da Praia & 89 \\
\hline Pilar e rua do Paço & 24 \\
\hline Santo Antonio $1^{\mathbf{0}}$ distrito & 49 \\
\hline Santo Antonio 2 ${ }^{\mathbf{~}}$ Capela do Resgate) & 26 \\
\hline Penha & 88 \\
\hline Victoria & 39 \\
\hline Total & 547 \\
\hline
\end{tabular}

Fonte: Freitas Henriques, 1872. Quadro elaborado pela autora.

Contudo, avaliou negativamente em 1872 a criação destas cadeiras de aulas noturnas por aumentarem os dispêndios, que alegou não poderiam ser mantidos pelo municipio nem pela tesouraria provincial e por não manterem alta frequência "[...] conservadas as mais conmcorridas, a despeza sera proveitosa." (ROCHA, 1872, p. 09). Expressou que contava com o "[...] entusiasmo da sociedade para supri-las [...]" através da filantropia, para instruir os trabalhadores como afirmou já acontecer nas "Sociedades de Oficio e nas dedicadas aos desvalidos e órfãos.” (ROCHA, 1872, p. 09). 


\section{Revista HIIST'TEIDBR On-line}

Ante esta posição negativa da diretoria da instrução pública, na manutenção das escolas noturnas para adultos, alguns professores criaram alternativas a falta de verbas públicas para mantê-las, o que indicia quanto a existência de procura por parte de alunos. Estas escolas noturnas foram categorizadas nos relatórios da presidência da província e naqueles dos diretores de instrução pública como particulares. Dentre as registradas nestes documentos, estão aquelas instaladas em cidades e vilas do interior, algumas bastante distantes da capital como Alcobaça, Brotas de Macaúbas ou Umburanas do termo de Caitité, estas duas últimas no extremo oeste da província.

Quadro 03 - Escolas para adultos ou noturnas criadas por particulares em 1871.

\begin{tabular}{|l|l|l|}
\hline Local & Professor & Freq. \\
\hline $\begin{array}{l}\text { Freguesia dos Mares, } \\
\text { capital. }\end{array}$ & $\begin{array}{l}\text { Reverendo Pároco D. Romualdo Maria Seixas } \\
\text { Barroso }\end{array}$ & 36 \\
\hline Cachoeira & Prof. Público Antonio Bahia da Silva Araujo & 101 \\
\hline Cruz das Almas & Professor Eusébio Harris de Castro & 51 \\
\hline Valença & Professor Simplicio J. Martins Paraguassu & 30 \\
\hline Aldeia & Professor Jonathas Martins Moscoso & 21 \\
\hline $\begin{array}{l}\text { Umburanas (termo de } \\
\text { Caitité) }\end{array}$ & Professor Martiniano de Santa Anna & 15 \\
\hline Saubara & Professor Joaquim José de Souza Mascarenhas Junior & 10 \\
\hline Monte Gordo & Substituto Alcides Jorge Ferreira & 10 \\
\hline Nazareth & Professor João Antonio de Vasconcellos & \\
\hline S. Gonçalo & Professor Manoel Pedro dos Santos Baptista & \\
\hline Brotas & Professor Manoel Luiz Gomes Vinhas & \\
\hline Alcobaça & Reverendo Vigário & 18 \\
\hline Baiacu & Professor Bernardino de Senna Calixto & \\
\hline Camizão & Advogado Capitão Luiz José de Amorim & \\
\hline
\end{tabular}

Fonte: Rocha, 1872. Quadro elaborado pela autora.

Quanto à aceitação e procura por parte dos trabalhadores adultos, o público alvo, constante nas fontes consultadas- os relatórios dos diretores de instrução pública, os relatórios dos presidentes da Província - a referência ao afã com que os trabalhadores, de todas as idades, teriam corrido a se matricular nas escolas noturnas.

Agradável não só ver o afan com que as procuram rapazes e velhos sentindo a necessidade de instruir-se, de sahir do estado de embrutecimento em que viviam, e dando ao estudo as horas que antes eram occupadas por um repouso excessivo sinao ate pelos vícios; e tambem ver o respeito, a attençao que prestam, o comportamento exemplar, enfim, que apresentam nas aulas, mais próprio de pessoas de refinada educação e esmerada illustração, do que de analfabetos, ignorantes do que devem a Deos, a seus pais e a sociedade. (ROCHA, 1872, p. 09). 
Mesmo relativizando o desejo de demonstração dos diretores da instrução pública, alguns dados evidenciaram este interesse. Foi excepcional a procura na pioneira da outras localidades a freqüência também foi elevada. Dezessete anos depois a Escola Nocturna Gratuita, regida pelo Professor Cincinato Ricardo Pereira da Franca na Cidade da Cachoeira, apresentava ainda 102 alunos matriculados. (SOUSA, 2006).

Porém, de forma geral, as fontes indiciam que após um sucesso inicial de matrícula, as escolas noturnas públicas foram ameaçadas de não terem continuidade por uma alegada falta de frequência por parte dos diretores de instrução pública. E a partir disto paulatinamente um pessimismo crônico marcou os discursos deste orgão em especial sobre a baixa freqüência. Em 1879, o reverendo Emilio Lobo, então diretor geral de instrução, as considerou ineficientes pela queda na procura que inicialmente acontecera.

No início de 1881, tendo como justificativa esta queda de freqüência, todas as aulas noturnas públicas da capital foram fechadas pelo padre Romualdo Maria de Seixas Barroso, quando da implementação do novo regulamento de instrução pública que ajudara a elaborar, conhecido como regulamento de Araujo Bulcão (NUNES, 2003) no intuito de as reformar e adequar ante os problemas de frequiência dos alunos e as reclamações de má conduta de professores que se avolumavam.

Quadro 4 - Frequência nas escolas noturnas para adultos- Salvador.

\begin{tabular}{|l|l|}
\hline ANO & ALUNOS \\
\hline 1873 & 648 \\
\hline 1874 & 343 \\
\hline 1875 & 275 \\
\hline 1876 & 264 \\
\hline 1877 & 372 \\
\hline 1878 & 420 \\
\hline 1879 & 308 \\
\hline 1880 & 284 \\
\hline Total & $\mathbf{2 9 1 4}$ \\
\hline
\end{tabular}

Fonte: Barroso, 1881. Quadro elaborado pela autora.

O diretor Romualdo Barroso informou ao recém empossado presidente da província João Lustosa da Cunha Paranaguá, conforme pedido por este, sobre um oficio encaminhado pelo cidadão Francisco Pereira do Nascimento Lisboa que solicitava que fosse reparado "[...] o grande mal que está soffrendo a população d'esta cidade com o fechamento das escholas nocturnas indebitamente ordenado por esta directoria [...]." (BARROSO, 1881, p. 49). Explicou o diretor geral da instrução pública que o fechamento das escolas noturnas fora provisório em 
razão da precariedade de suas condições de funcionamento a mobiliário, programa especifico e resultados de alunos prontos aos exames,

É claro, á vista do que fica exposto que não podião continuar as escholas nocturnas sem passarem por uma transformação. E porque, quando o mal é grande, é necessário muitas vezes arrancar para plantar e destruir para edificar, não á meu bel prazer, mas de accordo com o digno antecessor de V.Ex, mandei fechar provisoriamente as ditas escholas ate que se publicasse o Regulamento Interno das Escholas Primarias, onde há um capitulo especial sobre ellas, e, na qualidade de contractada, fossem providas nos termos do art 23 do regulamento em vigor. (BARROSO, 1881, p. 51).

As escolas noturnas foram remodeladas neste período de direção de D. Romualdo Barroso - 1881 a 1884. Mas neste período inicial de sua atuação, em 1881, foram reabertas apenas cinco públicas, com sugestão de recriá-las na Capital nas freguesias da Victoria, Rua do Passo, Conceição da Praia, Penha, Pilar, além de Brotas, semi ruralizada, que não as tivera na primeira experiência. Considerou também que deveriam ser instaladas nas cidades do interior mais populosas do interior como Cachoeira, Santo Amaro, Valença, Feira de Sant'Anna e Nazareth, atreladas as determinações do Tesouro Provincial

Quadro 05 - Escolas Noturnas em Salvador -1881

\begin{tabular}{|l|l|}
\hline Escola Noturna & Matricula \\
\hline Eschola da Sé & 80 \\
\hline Eschola de Sant'Anna & 60 \\
\hline Eschola de Santo Antonio & 43 \\
\hline Eschola de São Pedro & 60 \\
\hline Eschola dos Mares & 20 \\
\hline Total & 263 \\
\hline
\end{tabular}

Fonte: Barroso, 1881, p. 51. Quadro elaborado pela autora.

Dos freqüentadores, ainda que o público alvo genericamente fosse adultos trabalhadores, os registros indiciam que também que sujeitos na faixa de 14 e 18 se matricularam e frequentaram, como se refere o relatório do diretor de instrução Francisco José da Rocha, de 1872 , “[...] agradável não só ver o afan com que as procuram rapazes e velhos”. (ROCHA, 1872, p. 09). Concretamente, o mapa de 1888 da "Aula Noturna Gratuita" do professor Cincinato Ricardo Pereira da Franca, em Cachoeira, registrou que existiam três meninos entre 10 e 14 anos, assim como 35 entre 15 e 19, no bojo de 102 alunos matriculados. (SOUSA, 2006).

Para as mulheres também foram criadas aulas noturnas. Em 1883 uma aula feminina noturna primária foi instalada em Salvador, criada por Leopoldina Collet professora de língua pátria no Internato Normal de Senhoras, que antes era ministrada na sua própria casa, passando depois a sala anexa do Internato Normal de Senhoras. Infelizmente as fontes até agora não 


\section{Revista HIISTINIDIBR On-line}

ISSN : 1676-2584

Artigo

doi: $10.20396 /$ rho.v18i2.8645891

permitiram evidenciar quais mulheres a frequentaram, se libertas e livres pobres. Contudo, uma aula particular no interior da provincia indica ter aceitado mulheres do povo, pelo uso das categorias liberta e ingênua, no ano de 1888, conforme esta correspondência expedida por Eduardo Ramos, diretor de instrução, referente a uma aula noturna aberta no povoado do Sacco pela professora Maria Olimphia Oliveira,

12 de Junho de 1888

Secção: $1^{\mathrm{a}}$

$\mathrm{N}^{\mathrm{o}}: 817$

Respondendo ao officio de Vmcê de 11 do corrente, a que acompanhou o da professora da Cadeira de povoação do [Sacco, D. Maria Olympia de Oliveira,] participando ter aberto uma eschola nocturna para gratuitamente ensinar as ingênuas e libertas d'aquela localidade, recomendando-lhe que, em meo nome, agradeça e louve a referida Professora por esse acto de patriotismo e humanidade que acaba de praticar.

Deos Guarde a Vmcê.

Senr Dor. Director de Instrucção Publica

\{Satisfação em 14 de junho de 88\}

(RAMOS, 1888).

Outro limite desta instrução/educação noturna foi ter sido restritiva oficialmente para trabalhadores livres e libertos. Escravos não eram legalmente admitidos apesar dos indícios de defesa desta aceitação como uma das tensões do processo de implantação das aulas noturnas, com sujeitos e grupos defendendo o direito dos mesmos.

Os libertos, ao contrário eram aceitos na estratégia pretendida pelas elites dirigentes. Contudo, esta instrução prescrita e oferecida era a elementar, chamada de primária pois "[...] falando da instrução primaria que merece os cuidados da Constituição brasileira, disse que ela era a base de todo o progresso, a condição essencial das instituições políticas de um povo livre [...]". (MARTINS, 1870, p. 01).

Em relação ao aprendizado, os relatórios se queixam que os métodos de ensinar eram iguais ao diurnos, o que foi considerado erroneo pelo Cônego Emilio Lobo, em 1879, ao afirmar que "São úteis, são mesmo indispensáveis. Tem sido, porém, entre nós improductivos, e, direi ligeiramente, está falseada sua instituição, é que uma eschola de adultos não pode reger-se da mesma fôrma que uma eschola de meninos." (LOBO, 1879, p. 16).

Defendeu o cônego Emilio Lobo que as aulas noturnas não fossem dirigidas, termo para o exercício do magistério, pelos mesmos docentes públicos diurnos. Considerou que as mesmas eram pouco freqüentadas pela inoperância dos professores e não por falta de gosto da população

trabalhadora. Um dos pontos de sua análise era que o problema das escolas noturnas para adultos residia nos professores, os mesmos das aulas diurnas, que se estendiam nas escolas de $3^{\mathrm{a}}$ e $2^{\mathrm{a}}$ classe por duas sessões diárias, das 09 às 12 horas e das 13 às 16 horas, divisão do tempo escolar 


\section{Revista HIISTWIDBR On-lime}

que fora regulada pelo Regimento de Ensino de 1873, no seu inciso $\S 4^{\circ}$. Estas impressões foram reafirmadas por seu sucessor Romualdo Maria Barroso, nos seus relatórios de 1881 e 1883.

Quanto aos livros utilizados, eram os mesmos do diurno. Em ofício do inspetor literário do $2^{\circ}$ Distrito de 1879 foi registrado que os compêndios e demais materiais eram iguais para ambos os turnos e tipos de escola, ainda que os públicos fossem diversos. Alguns destes títulos estão apresentados neste quadro abaixo referente a aula do Curato da Sé, referente aos dois primeiros meses de 1878, contendo o nome dos alunos. É possivel que fossem todos trabalhadores, e que se possa classificá-los como pobres por terem feito jus aos livros. Todos eram homens que já conheciam as bases da leitura pois dos doze, dez receberam livros de gramatica portuguesa. Apenas a dois foi distribuida a inicial cartilha de $\mathrm{ABC}$, material dos que se iniciavam nesta habilidade escolar.

Quadro 6 - Relação dos livros distribuídos na $1^{\mathrm{a}}$ cadeira da Eschola Noturna da Freguezia da Sé. (janeiro a março) 1878.

\begin{tabular}{|l|l|}
\hline ALUNO & LIVRO \\
\hline 1-Manoel Severiano & Gramattica e H. Fabre. \\
\hline 2-Luiz Philippe da C.ta & $2^{\circ}$ Livro ( de Abílio César Borges ?) \\
\hline 3-Firmino José da Boa Morte & Bom Homem Ricardo \\
\hline 4-Fiel Olavo & Carta de A-B-C \\
\hline 5-Athanazio Moreira & Grammatica. \\
\hline 6-Basilio Elesbão & " \\
\hline 7-Paulo Damião do Nascimento & " \\
\hline 8-Torquato Malaquias & " e H. Fabre. \\
\hline 9-Hermilio Leoncio & Carta de A.B.C. \\
\hline 10-Ivo de Souza Ribeiro & Grammatica e H. Fabre. \\
\hline 11-M.el Ambrosio & " \\
\hline 12-M.el Baptista de Azevedo & " e \\
\hline
\end{tabular}

Fonte: Lobo, 1879. Quadro elaborado pela autora.

Dos livros registrados, alguns estão com o título resumido ou só indicam o número da série de um conjunto de livros ou uma parte do nome do autor desta série, pois eram os mais adotados e conhecidos, no caso os livros de leitura do professor Abílio Cezar Borges, que fora diretor de ensino em 1856.

A análise da lista de livros doados elaborada pelo Professor Antonio Bahia indicia que dos alunos que os receberam metade teve apenas o prenome registrado, o que permite problematizar fossem libertos, contudo ainda são precisas listas de matrícula que permitam cruzar nominalmente com outros documentos, como assentamentos de batismos, de óbitos ou registros de trabalhadores. 


\section{Revista HIST'TEIDIBR On-lime}

ISSN: $1676-2584$

Artigo

doi: $10.20396 /$ rho.v18i2.8645891

No relatório de 1883, elaborado pelo reverendo Romualdo Maria Barroso, antigo defensor das mesmas, a visão sobre as escolas noturnas foi mais positiva, sendo as mesmas consideradas como beneficio aos trabalhadores. Referindo-se as escolas noturnas fora do Brasil,

Quanto ao programma de ensino, providenciei como foi possível no Regimento Interno das escolas.

Na Allemanha, na França, na Belgica, nos Estados-Unidos, o curso para os adultos divide-se em dous grãos-elementar e complementar.

O elementar corresponde, a menos, leitura, escripta, systema legal dos pesos e medidas, elementos de calculo e de língua nacional: o complementar, língua nacional, principalmente pátrias, noções de arithemetica, desenho, elementos de geographia e historia principalmente pátrias, noções de higyene, noções de direito constitucional para o sexo masculino e de economia domestica para o feminino. (BARROSO, 1883, p. 28-29).

Em 1881, o conteúdo da instrução elementar sofreu regularização pelo Regimento Interno da Instrução Pública.Fica evidente que foi incluído no programa de ensino das escolas noturnas na Bahia elementos úteis a vida do trabalho, que as escolas noturnas já estavam incorporando matérias práticas no curso elementar consideradas necessárias aos ofícios das classes laboriosas. Na escrita do diretor de instrução pública Romualdo Barroso

No Regimento Interno reduzi o ensino à leitura, escripta, elementos de grammatica portuguesa, Arithmetica (operações elementares com apllicações praticas, fracções decimaes e ordinarias, systema métrico decimal, proporções e suas applicações) desenho linear, religião e civilidade.

Poder-se-hia ajuntar- elementos de geographia e historia pátrias, e de hygiene, sendo dado o ensino d'estas ultimas disciplinas por meio de leituras explicadas.

Resta attender-se á ultima necessidade- mobílias apropriadas. (BARROSO, 1883, p. 29).

As fontes ainda permitem afirmar que as escolas noturnas na província baiana aumentaram quantitativamente entre 1888 e 1889 , no decorrer das tensões abolicionistas e do pós-abolição para educar libertos, libertandos e ingênuos. Foram escolas para adultos, mas que enfatizaram os libertandos - os escravos recém emancipados- como a escola da Associação Treze de Maio, criada por um grupo de patronos para educar os libertandos, como analisou Silva (2007).

Quanto a sua antiga feição no período pré-abolição a última referência é do mês de outubro de 1889, fronteira do final do Império. Sousa a considerou registro privilegiado das experiências escolares de homens livres pobres, ex-escravos e ingênuos. A côr destes anônimos não é registrada na documentação, um mappa de aula, mas perceptivel na enunciação do professor ao indicar quais eram os sujeitos de sua aula noturna: os libertos, libertandos e ingênuos, na sua escola, “[...] com matriculla de 102 individuos sendo a maioria d'aquelles que 


\section{Revista HIIST'NADBR On-line}

ISSN: $1676-2584$

Artigo

doi: $10.20396 /$ rho.v18i2.8645891

tiveram pleno gozo dos seus direitos no dia 13 de maio de 1888" (FRANCA, 1889b), do professor Cincinato Ricardo Pereira Franca, em Iguape, termo da cidade de Cachoeira, no recôncavo baiano.

Para o professor Cincinato Franca, este ensino de instrução noturna era uma forma de doação abolicionista. Seu oficio informa que as despesas eram mantidas por ele, na sua expressão, "[...] até o dia 13 de Maio de 1888 as minhas custas." (FRANCA, 1889b). Recebia a ajuda do "[...] cidadão Candido Jozé Abbade meu ajudante gratuito desde o dia da inauguração do referido curso." (FRANCA, 1889b). Na sua escrita, seu intuito ao ministrar esta aula noturna a adultos trabalhadores era de permitir aqueles que, ainda sob um olhar também preconceituoso, apresentou como os "[...] infelizes que vagam nas trevas da ignorância, sem luz n'alma nem vida na inteligência [...]”. (FRANCA, 1889b). Uma fala em consonância com as representações correntes sobre os trabalhadores em geral os libertos e libertandos na época.

Em 08 de dezembro de 1889 o professor Cincinato Franca enviou o mapa da sua aula, que era obrigatório aos professores das aulas públicas desde o regimento de ensino de 1842 . O professor Cincinato Franca, formado aluno-mestre pela Escola Normal de Homens da província, informou ao governador do estado que,

Tenho honra de levar, as vossas mão, o mappa e juncto, as escriptas dos alumnos de differentes cursos que prestaram exame na noite de 3 do corrente mez na minha escola nocturna gratuita, creada no $1^{\circ}$ de Abril de 1887 para instrucção do povo. (FRANCA, 1889a).

Relatou ainda neste oficio que no ano de 1887 a escola recebeu apoio material do “Cidadão Coronel R. Martins Ramos." (FRANCA, 1889a). O professor Cincinato Franca indicou que este oferecia suprimentos indispensaveis à aula noturna entre maio de 1888e dezembro de 1889 como "[...] tinta, papel, giz, pena, kerosen e água, o que effectuou sem interrupção.” (FRANCA, 1889a).

Contudo, considero que também foi uma tática para conseguir materiais da cultura escolar para sua aula noturna gratuita junto ao novo governo republicano. Argumentou que a matrícula de cento e dois alunos (102) alunos e a freqüência diária que tinha na sua aula, que "[...] era e é de setenta á mais e o adiantamento se tem tornado digno de admiração de todos n'esta cidade." (FRANCA, 1889b), fazia juz ao apoio solicitado. A procura pela escola noturna fora tão grande que tinha fechado a matrícula por falta de espaço para acomodar mais alunos,

[...] portanto aproveito a occasião para evocar a valiosa protecção de V.Excia para estes infelizes que vagam nas trevas da ignorância, sem luz n'alma nem vida na intelligencia, e, que, somente a escola a essência de Deus dará a elles 'a fragancia da vida moral bafejada pelas auras celestes da sciencia. (FRANCA, 1889b). 


\section{Revista HIISTINIDIBR On-line}

ISSN : 1676-2584

Artigo

doi: $10.20396 /$ rho.v18i2.8645891

Ao final desta correspondência, encaminhada em outubro de 1889 solicitou ainda que "[...] por amor a pátria, a civilização e a Deus uma casa para à noite ensinar a numero illimitado d' aquelles que na infancia vedaram-lhe o livro." (FRANCA, 1889b). Se recebeu este material ou a subvenção para pagar o local de aulas a documentação não indicia. $\mathrm{O}$ oficio não apresenta resposta oficial e da mesma forma um segundo, encaminhado naquele último mês do Império. Da mesma forma sem resposta registrada quanto ao segundo oficio, o de dezembro de 1889, já estão recebido pelos gestores republicanos.

O que a documentação encontrada indicia é que esta escola noturna teve fim no início do ano de 1890, com a perseguição ao professor Cincinato Franca em Cachoeira por sua atuação como abolicionista e como educador de trabalhadores pobres, livres, libertos e libertandos.

\section{CONSIDERAÇÕES FINAIS:}

$\mathrm{O}$ artigo, aqui apresentado, sinaliza uma pesquisa em andamento sobre a escolarização de pobres e trabalhadores na Bahia, entre o século XIX e os primeiros anos do pós abolição. A assunção desta categoria temporal na problematização é em razão de alguns dos sujeitos da investigação serem egressos da escravidão, enquanto libertos e libertandos Fraga (2006). Parcelas destes tinham relações com sujeitos que experienciaram a escravidão enquanto filhos e netos de ex-escravos, mesmo que já nascidos livres, mas criados nas redes e liames das memórias do cativeiro como argumentam Mattos \& Rios (2005).

$\mathrm{O}$ argumento chave deste artigo é que as escolas noturnas para adultos foram criadas no contexto da década de 1870, articuladas aos debates, tensões e propostas abolicionistas, é evidente nas fontes consultadas, especialmente nos relatórios dos diretores de instrução, que continuadamente registram as estratégias dos setores dirigentes quanto aos conflitos e disputam dentro do próprio grupo. Estas estratégias se expandiram pela década seguinte de 1880, incorporando a diversidade de experiências de liberdade antes e após o 13 de maio de 1889, como as pressões por parte dos trabalhadores livres/libertos e os novéis libertandos pelo acesso a Instrução como tática de inserção social.

Uma questão a ressaltar foi que, criadas para adultos no sentido pleno deste termo no período, aqueles acima de 21 anos, as fontes evidenciam também uma importante procura por parte de um conjunto de pessoas, na faixa de 14 a 20 anos, não aceitos nas aulas diurnas, mas que buscaram a instrução nos interstícios permitidos pelas aulas noturnas.

Quanto às tensões e limites destas escolas noturnas para adultos, interessa dar continuidade na pesquisa a aspectos como a cultura escolar, tanto nas suas experiências do cotidiano como no referente ao material escolar e as práticas de ensino. Também importante as 
questões referentes ao dispêndio, tanto nas públicas como nas particulares, que apontam as táticas dos sujeitos trabalhadores em suprir o desejo pela Instrução. São questões em encaminhamento, com fontes já levantadas e em análise.

Por fim, um último ponto a ser ampliado, articulado profundamente ao imaginário das décadas de 1870 a 1890 , é referente ao medo das elites quanto à presença de homens trabalhadores livres e libertos, na maioria para a Bahia, homens de côr, homens negros, nos embates do pós abolição.

\section{REFERÊNCIAS}

ALMEIDA COUTO, J. J. de. Província da Bahia, Reforma da Instrução. Presidente José Eduardo Freire de Carvalho, Tipografia do Correio da Bahia, 1873.

ANANIAS, M. Propostas de educação popular em Campinas: "as aulas noturnas". Campinas, SP, Cadernos Cedes, ano 20, n. 51, nov. 2000.

BARREIRO, J. C. Imaginário e viajantes no Brasil do século XIX. São Paulo: Ed. da UNESP, 2002.

BARROSO, R. M. de. S. Relatório da Instrucção Publica. Anexo a Falla do Presidente Antonio Araújo Bulcão, Tipografia do Diário da Bahia, 1881.

BARROSO, R. M. de. S. Relatório da Instrucção Publica. Anexo a Falla do Presidente Antonio Araújo Bulcão, Tipografia do Diário da Bahia, 1882.

BARROSO, R. M. de S. Relatório da Instrucção Pública. Anexo a Falla do Presidente João Lustosa da Cunha Paranaguá, Tipografia do Diário da Bahia, 1883.

COSTA, A. L. J. A luz das lamparinas: escolas noturnas para trabalhadores no município da Corte. In: REUNIÃO ANUAL DA ASSOCIAÇÃO NACIONAL DE PÓS-GRADUAÇÃO E PESQUISA EM EDUCAÇÃO, 30., 2007, Caxambu, MG. Anais Eletrônicos... Caxambu, MG: ANPED, 2007. p. 01-06. Disponível em: <http://www.anped.org.br/biblioteca/item/luzdas-lamparinas -escolas-noturnas-para-trabalhadores-no-municipio-da-corte>. Acesso em: 02 abr. 2016.

EISENBERG, P. Homens esquecidos. Campinas: Ed. da UNICAMP, 1989.

FRAGA, W. Encruzilhadas da liberdade: histórias de escravos e libertos na Bahia, 18881910. Campinas, São Paulo: Ed. da UNICAMP, 2006. 
FRANCA, C. R. P. da. Oficcio da Escola Nocturna Gratuita da Cidade de Cachoeira. Illmo Exmo. Snr Dr DGIP da Bahia. O Professor Publico Nocturno, Cincinato Ricar do Per ${ }^{a}$ da França, 08/12/1889. 1889a. 1 p.

FRANCA, C. R. P. da. Oficcio da Escola Nocturna Gratuita da Cidade de Cachoeira. Illmo Exmo. Snr Dr DGIP da Bahia. O Professor Publico Nocturno, Cincinato Ricar do Per ${ }^{\mathrm{a}} \mathrm{da}$ França, 13/10/1889. 1889b. 1 p.

FREIRE, A. M. Analfabetismo no Brasil. São Paulo: Cortez, 1989.

FREITAS HENRIQUES, A. de. A. Relatório do Presidente da província da Bahia, Desembargador Antonio Araujo de Freitas Henriques, Tipografia do Correio da Bahia, 1872.

LOBO, E. F. L. Relatório do Diretor Geral de Instrução Pública cônego Emilio Freire Lopes Lobo. Seção "Escholas Nocturnas". Anexo ao Relatório do Presidente da Província da Bahia, Tipografia do Diário da Bahia, 1879.

MAC CORD, M.; ARAUJO, C. E.; GOMES, F. Rascunhos cativos: educação, escolas e ensino no Brasil escravista. Rio de Janeiro: 7 Letras, 2017.

MAC CORD, M. Artífices da cidadania: mutualismo, educação e trabalho no Recife oitocentista. Campinas, São Paulo: Ed. da UNICAMP, 2012.

MARTINS, F. G. Relatório à Assembléia Provincial da Bahia do Presidente da Província da Bahia, Barão de São Lourenço. Instrução primaria. Tipografia do Jornal da Bahia, 1870.

MARTINS, F. G. Relatório à Assembléia Provincial da Bahia pelo Presidente da Província da Bahia, Barão de São Lourenço. Instrução primaria. Tipografia do Jornal da Bahia, 1871.

MATTOS, H.; RIOS, A. L. Memórias do cativeiro: família, trabalho e cidadania no pósabolição. Rio de Janeiro: Civilização Brasileira, 2005.

MOURA, T. A. P. de. Inspector litterario do $2^{\circ}$ Districto, 1878.

NASCIMENTO, A. A. Dez freguesias da cidade de Salvador. SSa: Fundação Cultural do Estado da Bahia. Secretaria de Cultura e Turismo, 1986.

NOGUEIRA, V. L. A escola primária noturna em Minas Gerais (1891-1924). Belo Horizonte, MG: Mazza, 2012.

NOGUEIRA, V. L. Filantropia e educação de adultos livres, libertos e escravos na província de Minas Gerais (1870-1880). In: NOGUEIRA, V. L. (Org.). População negra, escravismo e educação no Brasil: séculos XIX e XX. Belo Horizonte, MG: Mazza, 2015. p. 123-149. 
NUNES, A. A. A formação dos sistemas públicos de educação no séc. XIX e sua efetivação na província da Bahia. SSa: RIGHBa, v. 99, p. 75-113, 2004.

NUNES, A. A. Política educacional no início da república na Bahia: duas versões do projeto liberal. 2003. Tese (Doutorado em Educação) - Faculdade de Educação, Universidade Federal da Bahia, Bahia, 2003.

PERES, E. T. Os cursos masculinos de instrução pública primária da Biblioteca Pública Pelotense (BPP). Cadernos de Educação, Pelotas, n. 6, p. 41-70, jan./jun. 1996.

PERES, E. T. Templo de Luz. Pelotas, RS: Ed. da UFPel, 2001.

RAMOS, E. Oficcio da Diretoria de Instrução Pública da Bahia, 12/06/1888. 1p.

REIS, J. J. A Greve negra de 1857. Revista USP, São Paulo, n. 28, p. 06-29, 1993. Dossiê: Povo Negro.

REIS, J. J. De olho no canto: trabalho de rua na Bahia na véspera da abolição. Revista AfroÁsia, n. 24, p. 199-242, 2000. CEAO/UFBa/Fundação Clemente Mariani.

RIZZINI, I. O cidadão polido e o selvagem bruto: a educação dos meninos desvalidos na Amazônia Imperial. 2004. Tese (Doutorado em História Social) - Programa de Pós-Graduação em História Social, Instituto de Filosofia e Ciências Sociais, Universidade Federal do Rio de Janeiro, Rio de Janeiro, 2004.

ROCHA, F. J. da. Relatório do Diretor Geral de Instrução Pública Francisco José da Rocha. Anexo ao Relatório do Presidente da Província, Antonio Araújo de Freitas Henrique, Tipografia do Correio da Bahia, 1872.

SCHUELER, A. F. Educar e instruir: a instrução popular na Corte Imperial (1870-1889). 1997. Dissertação (Mestrado em História Social das Idéias) - Universidade Federal Fluminense, Niterói, RJ, 1997.

SILVA, R. T. C. Caminhos e descaminhos da abolição. Escravos, senhores e direitos nas últimas décadas da escravidão. (Bahia, 1850-1888). 2007. Tese (Doutorado em História) Universidade Federal do Paraná, Curitiba, 2007.

SOUSA, I. C. de. Escolas ao povo: experiências de escolarização de pobres na Bahia - 1870 a 1890. 2006. Tese (Doutorado em História Social) - Pontifícia Universidade Católica de São Paulo, São Paulo, 2006.

SOUSA, I. C. de. Regeneração pela instrução: a cadeira pública da casa de prisão com trabalho - Bahia, 1871-1889. In: ANANIAS, M. et al. (Org.). Temas sobre a instrução no Brasil Imperial (1822-1889). Campina Grande, PB: Ed. da UFPB, 2014. v. 2. 


\section{Revista HIIST'TEIDIBR On-line}

Notas

${ }^{1}$ Doutora em História Social pela PEPGHS-PUC/SP 2006. Professora Adjunta UEFS-Ba DCHF/Área de História. Pesquisadora em História da Educação e da Infância-coordenadora do Grupo HISTEICE (História da Educação, Infância e Culturas Escolares).

Submetido em: 01/05/2016

Aprovado em: 12/04/2018

Publicado em: 03/07/2018 